


\section{DISCLAIMER}

This report was prepared as an account of work sponsored by an agency of the United States Government. Neither the United States Government nor any agency Thereof, nor any of their employees, makes any warranty, express or implied, or assumes any legal liability or responsibility for the accuracy, completeness, or usefulness of any information, apparatus, product, or process disclosed, or represents that its use would not infringe privately owned rights. Reference herein to any specific commercial product, process, or service by trade name, trademark, manufacturer, or otherwise does not necessarily constitute or imply its endorsement, recommendation, or favoring by the United States Government or any agency thereof. The views and opinions of authors expressed herein do not necessarily state or reflect those of the United States Government or any agency thereof. 


\section{DISCLAIMER}

Portions of this document may be illegible in electronic image products. Images are produced from the best available original document. 


\title{
Experimental Investigation of the Removal of Hydrogen Sulfide From Geothermal Steam
}

\author{
ER-896 \\ Technical Planning Study 76-656 \\ Final Report, September 1978
}

Prepared by

AIR POLLUTION SYSTEMS, INC.

18642-68th Avenue, South

Kent, Washington 98031
Principal Investigators
James Schwab
David Goodson
Peter Milovsoroff

\section{Prepared for}

\section{Electric Power Research Institute}

3412. Hillview Avenue

Palo Alto, California 94304

EPRI Project Manager

Vasel Roberts

Fossil Fuel and Advanced Systems Division 


\section{ABSTRACT}

With the advent of geothermal steam power production, there arises with it the necessity of removing undesirable corrosive compounds such as Hydrogen sulfide. The influence this compound has on both the environment and equipment utilized in its production is well known and presents a technical challenge. The most satisfactory method of removal would be to remove Hydrogen Sulfide upstream of the turbine, if practicable. Earlier work with the Hi Intensity Ionizer (developed under EPRI contract RP725) suggested that high intensity corona might be adopted to removal of Hydrogen Sulfide from geothermal steam. The purpose of this experimental investigation was to examine the technical feasibility of utilizing this process to remove Hydrogen Sulfide from geothermal steam.

These tests demonstrated no detectable conversion on $117^{\circ} \mathrm{C}$ steam at $100 \mathrm{psi}$ (> 3\% detectable threshold). Tests with Nitrogen likewise showed no conversion. Tests with air showed substantial conversion of Hydrogen Sulfide to Sul fur Dioxide. No other intermediate or final products were identified. 


\section{EPRI PERSPECTIVE}

\section{PROJECT DESCRIPTION}

This final report, "Experimental Investigation of the Removal of Hydrogen Sulfide from Geothermal Steam," is the conclusion of a small project prompted by results of work with high intensity ionization to remove impurities from air and other gases under EPRI Project RP725. The approach was to process simulated geothermal steam through one of the existing ionizers at pressures up to those encountered at the Geysers and at field strengths at which the ionizer is capable of operating. The concept was to direct the steam and hydrogen sulfide mixture through the most intense part of the corona where the high electrostatic field causes high electron energies as a result of collisions between gas molecules. This was expected to promote decomposition of hydrogen sulfide molecules, the radicals of which might be recombined into other removable species.

\section{PROJECT OBJECTIVE}

The objective of this project was to develop experimental data to assess the applicability of high intensity ionization as a method for removing hydrogen sulfide from geothermal steam upstream from the turbine.

\section{CONCLUSIONS AND RECOMMENDATIONS}

Under the test conditions, the high intensity ionizer did not remove any measurable quantity of hydrogen sulfide from the simulated geothermal steam. While this one set of experiments may be inconclusive, it demonstrates that in its present state of development the concept is not a viable alternative for hydrogen sulfide removal from geothermal steam.

Vasel Roberts, Project Manager

Fossil Fuel and Advanced Systems Division 


\section{CONTENTS}

\section{Page}

Introduction

System Description

Performance Characteristics

Test Results

Examination of Mass Spectra for the Formation of Ammonium Compounds

Observation of Reactor Pressure Change with Ionizer "On" Condition 
SUMMARY

A technique for applying hi-intensity corona energy to a synthesized geothermal $\mathrm{H}_{2} \mathrm{~S} /$ steam gas was tested. Mass spectrographic analysis showed no removal of $\mathrm{H}_{2} \mathrm{~S}$ with steam due to difficulty in obtaining stable operating parameters. Conversion in laboratory air and compressed gas at attractive conversion efficiencies however was observed. Recommendations for reactor design changes such that stable power input may be obtained are recommended. 


\section{INTRODUCTION}

The objective of this study was to make a preliminary qual itative assessment of the feasibility of removing Hydrogen Sulfide and other chemical species from geothermal steam at wellhead conditions by processing the steam thru a high intensity corona discharge. The explorations are based on the concept of using high electrostatic fields to convert chemical species and the experiments run on apparatus similar to APS's Ozone Generator. The heart of the concept is a high intensity corona discharge maintained by a disc cathode and cylindrical anode. Gas is directed thru the most intense part of the corona (region nearest cathode). Here the high electrostatic fields ( $>30 \mathrm{kV} / \mathrm{cm}$ ) cause high electron energies ( $>4 \mathrm{ev}$ ) to be attained between collisions with gas molecules. Many collisions in this region statistically are of sufficient energy to promote decomposition of molecules. Hopefully then, the various radicals present can then recombine to form removable species either in the form of aerosols or solids.

Results of a similar process in the APS ozone reactor are reported to be $\sim 50$ - 100 ppm 0zone generated per ionizer stage from air with $5-10 \mathrm{kWh} / \mathrm{lb}$ ozone required. In this case, the oxygen in air is decomposed into nascent oxygen by electron excitation. The nascent oxygen then "oxidizes" oxygen molecules to Ozone upon collision.

For geothermal steam gas composition, the resultant species are difficult to predict. It is expected that oxidation of the Hydrogen Sulfide by the decomposition products of water and carbon dioxide will occur. Oxidation of Sulfur Dioxide in corona to Sulfuric Acid mist with an attractive energy consumption has been reported at Georgia Tech. Corona reaction effects have been observed in EPRI RP725-1 testing of coal combustion gas components at $300^{\circ} \mathrm{F}$, particularly Carbon Monoxide and Nitrous oxides. At the near saturated steam conditions present, it is expected that oxidized Hydrogen Sulfide will be strongly nucleating and form a fine particulate aerosol. If so, a precipitation section could be added between reaction stages to collect the aerosol mist. 
A similar concept was used on high opacity tail gas from a phosphate rock dryer. The gases were pre-scrubbed and cooled (to $80^{\circ} \mathrm{F}$ ) and passed thru the reactor. Although the particulate grain loading was light $(<0.1 \mathrm{gr} / \mathrm{scf}$ ) the seven stage reactor/precipitator collected $\sim 1-2 \mathrm{gph}$ of liquid ( $\mathrm{ph} \sim 3.0$ ) from $\sim 750 \mathrm{cfm}$ of gas. Since the gases were thoroughly demisted prior to entering the reactor and outside air temperature $\sim 80^{\circ} \mathrm{F}$, it is unlikely that the liquid came from water drop collection or wall condensation. The reactor/precipitator successfully el iminated the opacity and consumed only 160 watts $/ 1000 \mathrm{cfm}$.

\section{SYSTEM DESCRIPTION}

The basic experimental arrangement utilized is shown in Figure 1 of this report. Photos of the experimental arrangement are shown in Figure 2. Steam generated by an oil fired boiler is super heated and injected with the test gases methane, ammonia, carbon dioxide, and hydrogen sulfide. The gas is then routed into the experimental reactor. A small change in the gas flow arrangement allowed the system to be operated on pure nitrogen, compressed air or a combination of carbon dioxide and nitrogen. It was also possible to operate the system on laboratory air at minimal air flows and slightly negative pressure $(-0.1 \mathrm{psig})$.

Once the gas stream mixture is superheated, it is routed thru the experimental reactor at various conditions of flow, pressure and temperature. Following passage thru the reactor, a side stream sample is routed past an adjustable leak orifice so that the chemical composition of the test gas may be monitored by mass spectrographic analysis (Finnigan Model 400). The reactor is provided with multiple variacs and heaters to control the insulator purge gas temperature and to heat the reaction chamber wall (anode) to help control condensation. The reaction chamber is also provided with a viewing port to observe corona under test conditions.

The reactor chamber consisted of a flanged stainless steel tube (anode) with a high voltage buss bar containing the electrodes (cathodes) positioned axially on the tube. Cathodes selected for this work were made of stainless steel. In an attempt to maximize the gas mixture exposure to as much input power as possible, up to five electrodes were used in some of the tests, however, due to electrical instabilities caused from condensation of water on the electrodes and buss system, the number of electrodes was 
reduced to two or three in order to obtain a stable operating condition.

Following the reaction chamber and gas analysis section is an orifice plate and differential manometer to measure actual gas flow. The total system mass flow was controlled by an exit valve downstream of the orifice plate.

Electrical isolation at high operating voltages in steam (100 kVdc) was maintained by the design of a special nitrogen purged insulator compartment. The region surrounding the electrical insulator was maintained at a slightly higher pressure than of the steam in the reactor, thus insuring positive flow of nitrogen thru the insulator chamber. The nitrogen heating system provided gas temperatures sufficiently high to pre-heat the insulator compartment and prevent condensation and shorting. The Nitrogen purge gas was then routed into the reaction chamber and mixed with the steam. In situations where tests were desired without Nitrogen, Carbon Dioxide was substituted.

The power supply utilized for these tests was a Universal Voltronics Model BPO100-5.5. This set provides positive or negative high voltage at $<5 \%$ RMS ripple and $<10 \%$ regulation. Test gases and standards for the Finnigan 400 Quadrupole Mass Spectrometer were supplied by Union Carbide Linde and metered into the gas stream by precision flowmeters. Concentrations were confirmed by mass spectrographic analysis.

\section{PERFORMANCE CHARACTERISTICS}

Full corona operation of the ionizer with steam was observed at pressures of 60 and 100 psi (see Figure 3). It was apparent that less corona was generated, however, than in compressed air at similar temperatures and pressures. Experimentation showed several problems that 1 imited the available power input and hence possible conversion efficiencies.

1. The physical nature of steam reduces corona current for a given voltage.

2. The appearance of condensation on the electrode system caused spurious emission and premature breakdown. Water drops become unstable at fields $(\sim 8 \mathrm{kV} / \mathrm{cm})$ well below the 30 to $40 \mathrm{kV} / \mathrm{cm} \mathrm{re}$ quired for reactor operation. The number of electrodes was reduced to obtain stable operation, however, this reduced total input power. 
3. The condensation problem increased at low flows because of reduced heat transfer at low mass flows. The lowest attainable mass flows $(21.1 \mathrm{cfm})$ were well above optimum.

4. It was determined that stable corona could only be achieved when condensation on the walls of the anode could be kept from occurring. An attempt to control the condensation by heating the area of high corona current deposition allowed voltage/current parameters to be established. However, at the anode temperatures necessary to maintain good operating conditions, the reactor wall temperature may have been too high to permit downstream condensation and collection of the corona reacted species.

5. Fluctuations of pressure from the boiler compounded this very delicate temperature condensation control problem.

Because of the limitations encountered with steam tests and the lack of tangible results, a set of tests were run with laboratory air, with compressed air, and with Nitrogen alone. Conversion with air as the background gas was checked by indirect means (measuring for Sulfur Dioxide formation) and was observed. (See test results.)

\section{TEST RESULTS}

No conversion of $\mathrm{H}_{2} \mathrm{~S}$ in steam at 60 psig was observed to a resolution of $3 \%$. This apparent lack of conversion is attributed to the marginal operating conditions attainable with the reactor design and serious condensation problems (discussed on page 4). A combination of low power input, short reaction times and difficulty in holding a delicate temperature balance are suspect as is possible inhibition of the reaction by water vapor. With compressed air employed as a background gas, conditions for conversion were met and conversion rates of $\mathrm{H}_{2} \mathrm{~S}$ to $\mathrm{SO}_{2}$ up to $32 \%$ were noted $\left(2000 \mathrm{ppm} \mathrm{H}_{2} \mathrm{~S}, 1.3 \mathrm{cfm}\right.$, 0.12 seconds of corona exposure time). Power consumption for these tests were approximately $15.8 \mathrm{Kwh} / \mathrm{lb} . \mathrm{H}_{2} \mathrm{~S}$ converted. It is interesting to note that conversion was noted at $12.4 \%, 8 \%$ on laboratory air containing $0.4 \%$ by vol. water vapor $\left(590 \mathrm{ppm} \mathrm{H} \mathrm{H}_{2} \mathrm{~S}, 430 \mathrm{ppm} \mathrm{NH}\right.$, and $1.3 \%$ vol $\left.\mathrm{CO}_{2}\right)$. Conversion was also noted in compressed air with $3 \% \mathrm{CO}_{2}$. However, no conversion was noted with Nitrogen as the main gas component mixed with $470 \mathrm{ppm} \mathrm{NH}, 2400 \mathrm{ppm} \mathrm{H}_{2} \mathrm{~S}$, and $\mathrm{CO}_{2}$ at $3.5 \%$ by volume. This conversion would appear to be due to the oxidizing effect of nascent oxygen produced in the corona. The reduction of $\mathrm{H}_{2} \mathrm{~S}$ to $\mathrm{S}$ was not observed by mass spectrographic means. The influence of feasibility of ozone injections into the synthesized gas stream from external sources was not investigated under. this contract. Other effects or 
results noted were as follows:

1. Conversion in air was observed to 60 psig (tests above 60 psig were not performed).

2. Conversion appeared inversely proportional to pressure, probably due to the added energy needed to overcome corona initiation conditions of the gas.

3. For the limited tests performed, conversion appears proportional to temperature (see Figure 5).

4. Conversion was proportional to power (at the same temperature and pressure).

5. $\mathrm{CO}_{2}$, up to $1.2 \%$ by volume and $\mathrm{CH}_{4}(500 \mathrm{ppm})$, had no apparent influence on conversion for cases tested.

6. The addition of $\mathrm{NH}_{3}$ (up to $885 \mathrm{ppm}$ ) had no effect on $\mathrm{H}_{2} \mathrm{~S}$ conversion but was observed to reduce both background $\mathrm{SO}_{2}$ level and the amount of conversion, proportionately implying a reaction between $\mathrm{NH}_{3}$ and $\mathrm{SO}_{2}$. No converted species was identified in the gas phase, however, leaving the products unknown.

It should be noted that these results were achieved with field exposure times $<1$ second and total reactor times (before analysis) $\leq 4$ seconds. Positive corona was tested but was not stable for temperatures and pressures up to $175^{\circ} \mathrm{C}$ and 100 psig with steam.

Current-Voltage curves for steam, for air at elevated temperature, and air at ambient temperature are shown for pressures from 0 to 100 psi in 20 psi increments (Figures 2 and 3 ). A reduction in the current with voltage for steam vs air may be observed (per expectation) in Figure 4. Conversion data for various conditions are given in Table I (page 11).

\section{EXAMINATION OF MASS SPECTRA FOR THE FORMATION OF AMMONIUM COMPOUNDS}

In the presence of steam at $60 \mathrm{psi}$ and $320^{\circ} \mathrm{F}$ a check was made for the formation of ammonium ions in the presence of corona. Bisulfate, monosulfide and hydrosulfide ions were not detected. (Minimum resolutions $\simeq 10 \mathrm{ppm}$.) An examination for $\mathrm{SO}_{3}$ showed no change at $5 \mathrm{ppm}$ resolution with maximum obtainable corona power. . The steam for this test was injected with $1.3 \%$ vol. $\mathrm{CO}_{2}, 250 \mathrm{ppm} \mathrm{H} \mathrm{H}_{2} \mathrm{~S}$, and $5 \% \mathrm{~N}_{2}$. At 100 psi less power input was available to the reactor than at $60 \mathrm{psi}$, so the investigation was not pursued further.

OBSERVATION OF REACTOR PRESSURE CHANGE WITH IONIZER "ON" CONDITION During the tests, a pressure differential was noted at the quadrupole mass 
spectrometer inlet during ionizer "on" conditions. This pressure differential ( $\simeq 3-6 \times 10^{-6}$ TORR) appeared as a very sensitive indicator of pressure change within the reactor vessel. Apparently condensation/nucleation was sponsored to some degree by the corona when the gas was routed through the most intense region of the corona.

A further test in an attempt to correlate this phenomenon was made by measuring the differences in condensate produced during ionizer "on" versus "off" conditions. Unfortunately, the main boiler pressure varied and the temperature of the steam varied within 3 to $5^{\circ} \mathrm{F}$. This temperature variation could not be controlled and affected the rate of condensation. This variation interfered with the condensate samples for ionizer on/off tests. Time and funding prevented further investigation. A check for $\mathrm{pH}$ of samples from two runs of ionizer "on", versus ionizer "off", indicated a shift toward an increased alkaline condition for the ionizer "on" case.

\section{RECOMMENDATIONS}

1. It appears that attractive conversion efficiencies in air are possible and may be applicable to superheated steam assuming precise controls on condensation and thermal equilibrium can be provided such that sufficient corona energy can be achieved. The primary problem is to get sufficient stable corona power input into the gas which can only be accomplished by modifying the reactor design. A multiple two stage system is proposed in which the anode region, being impacted with high corona current, would be heated above condensation temperature. Immediately downstream of this region the anode temperature would be lowered to promote condensation. The condensate would be removed before the next corona stage. This would allow the system to operate under maximum power conditions and allow condensation and removal of converted species before exposure to the high currents and fields opposite the corona discharge electrodes in the following stage. In addition to the above change, the electrode buss system must be provided with an electrically isolated thermal source, providing for adequate thermal isolation to prevent condensation from occuring on the electrodes and buss system. 
2. It is believed that the primary reaction involving $\mathrm{H}_{2} \mathrm{~S}$ in this process is through the production of nascent oxygen from the oxygen present in gas or from the breakdown of gases such as $\mathrm{CO}_{2}$ or $\mathrm{H}_{2} \mathrm{O}$. The high intensity ionizer geometry can be made to operate stabily in super heated steam and therefore may be useful in producing ozone within the gas stream by another electrode configuration developed at APS. In this scheme, oxygen would be introduced into a split electrode arrangement which should yield attractive ozone production rates at wellhead steam pressures. Since the ozone is produced at the oxygen inlet site to the gas stream, the ozone is then available to convert $\mathrm{H}_{2} \mathrm{~S}$ to $\mathrm{SO}_{2}$. The secondary process of changing the $\mathrm{SO}_{2}$ to an aerosol and collecting (if desirable) electrostatically in the condensation stage should then become viable.

The concept can also be investigated by producing ozone in an external APS reactor at wellhead pressures and temperatures from compressed air or oxygen and mixing it with the super heated steam. Conversion rates can be observed after a suitable residence time with the mass spectrometer.

3. The configuration and problems in obtaining stable reactor operation did not allow the examination of capturing $\mathrm{H}_{2} \mathrm{~S}$ or its corona, activated predecessors by acceptors or scavengers such as zinc, copper or iron oxides. Studies to determine the effectiveness of these materials when placed on the anode wall would be of interest along with the suggested design changes above. 
$\infty$

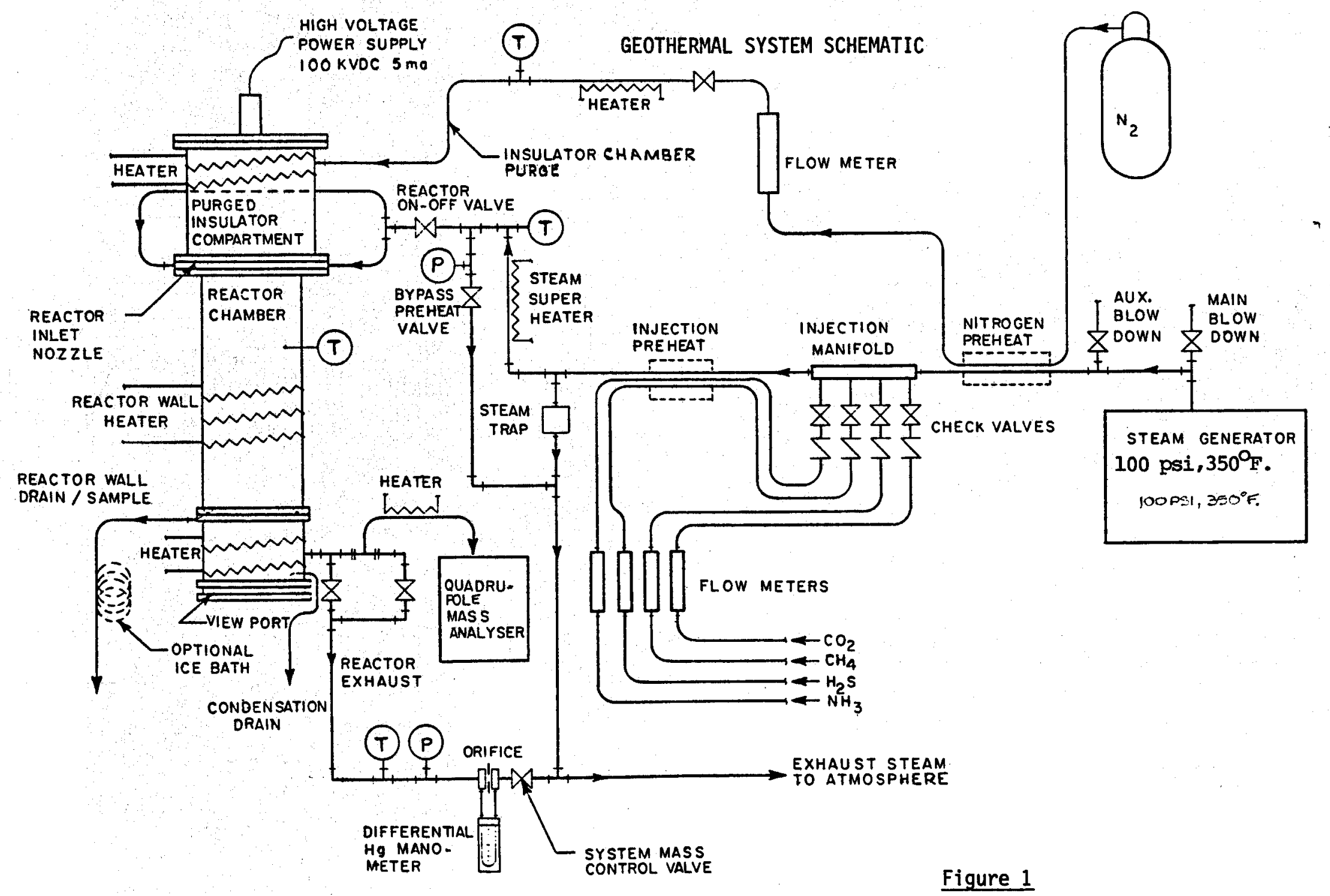




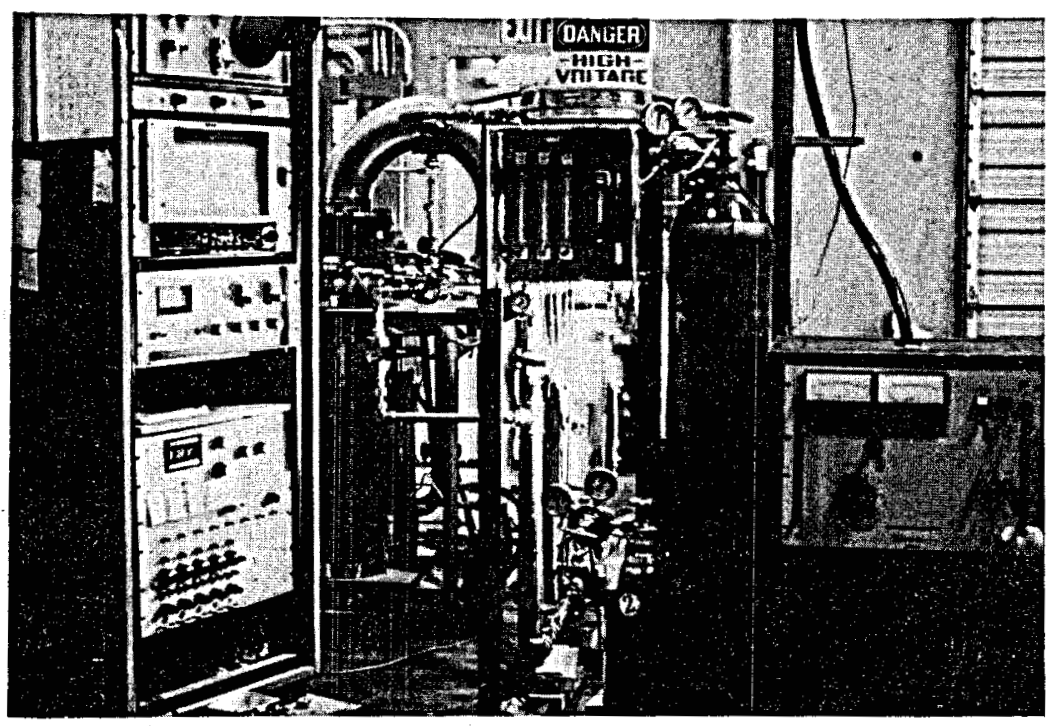

A) Basic Experimental Arrangement Showing (left to right) Quadrupole Mass Analyzer, Vacuum Support System, Geothermal Steam Corona Reactor and Power Supply.



B) Close Up of the Reactor Showing 1) Nitrogen Purged High Voltage Supply System, 2) Active Region Containing Anode/Cathode Section and Associated Gas Sampling Loop(3). 
SUMMARY OFTEST RESULTS

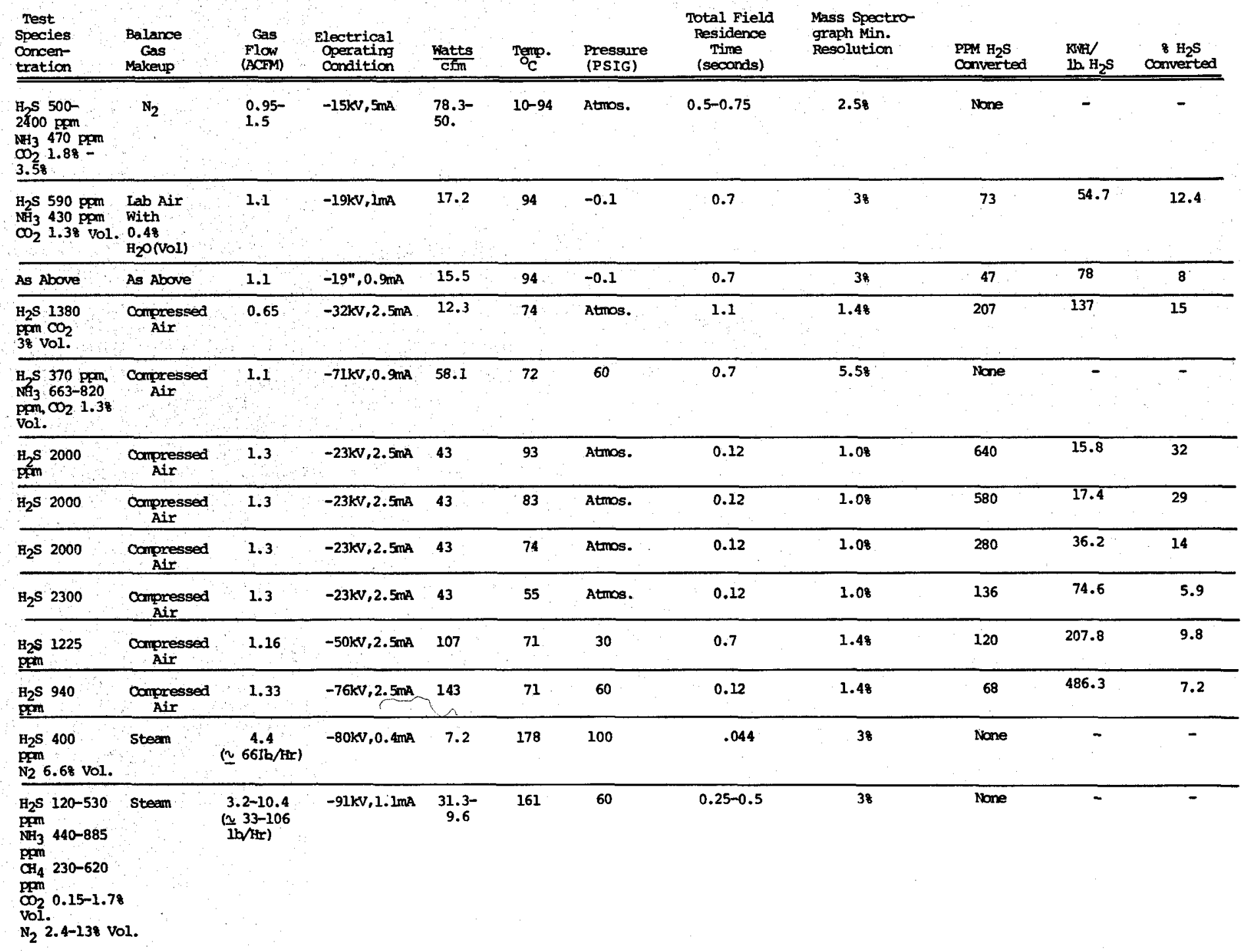


APS OZONE REACTOR

Compressed Air V-I

$16^{\circ} \mathrm{C}\left(61^{\circ} \mathrm{F}\right)$






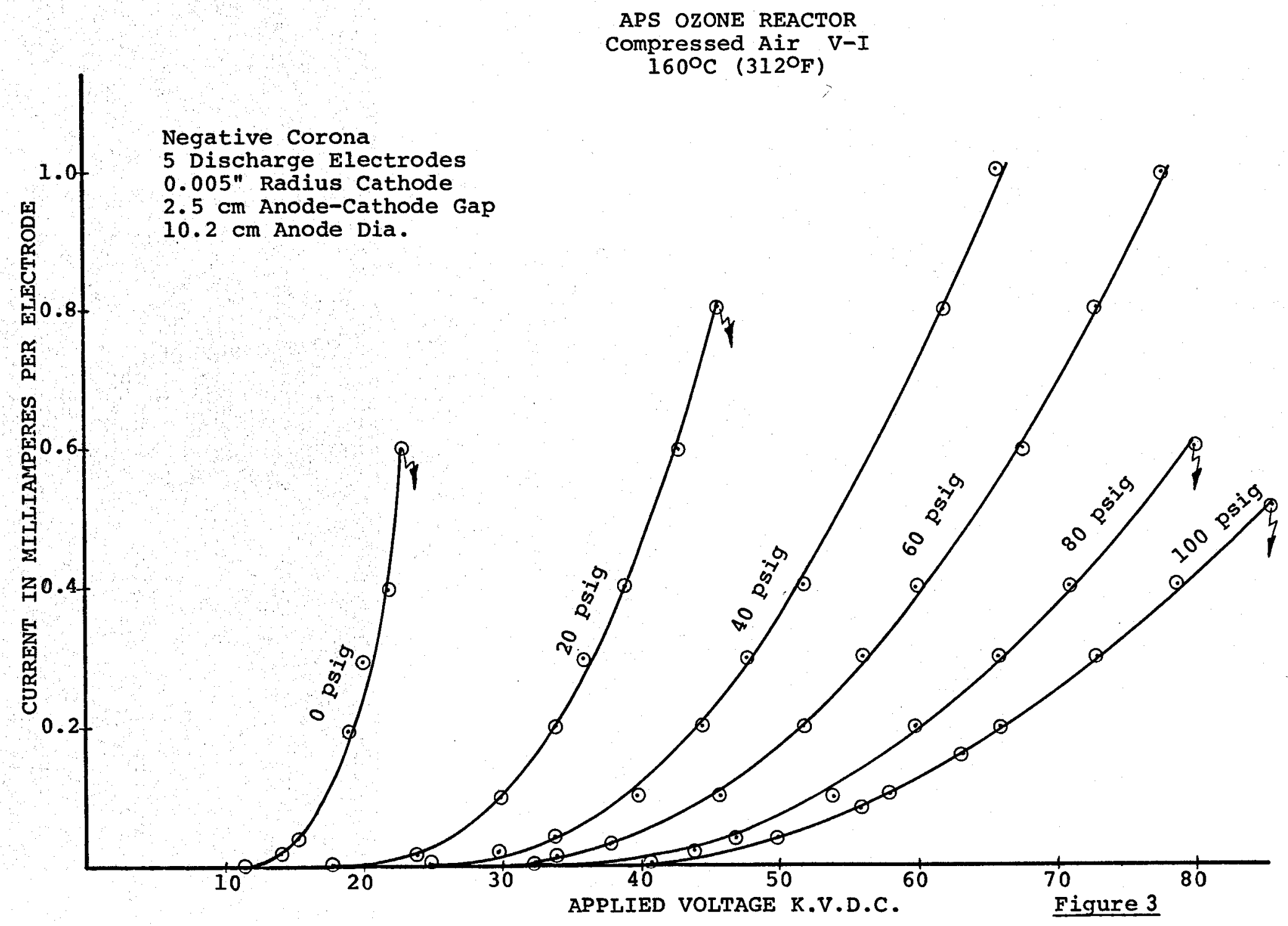


APS OZONE REACTOR STEAM V-I






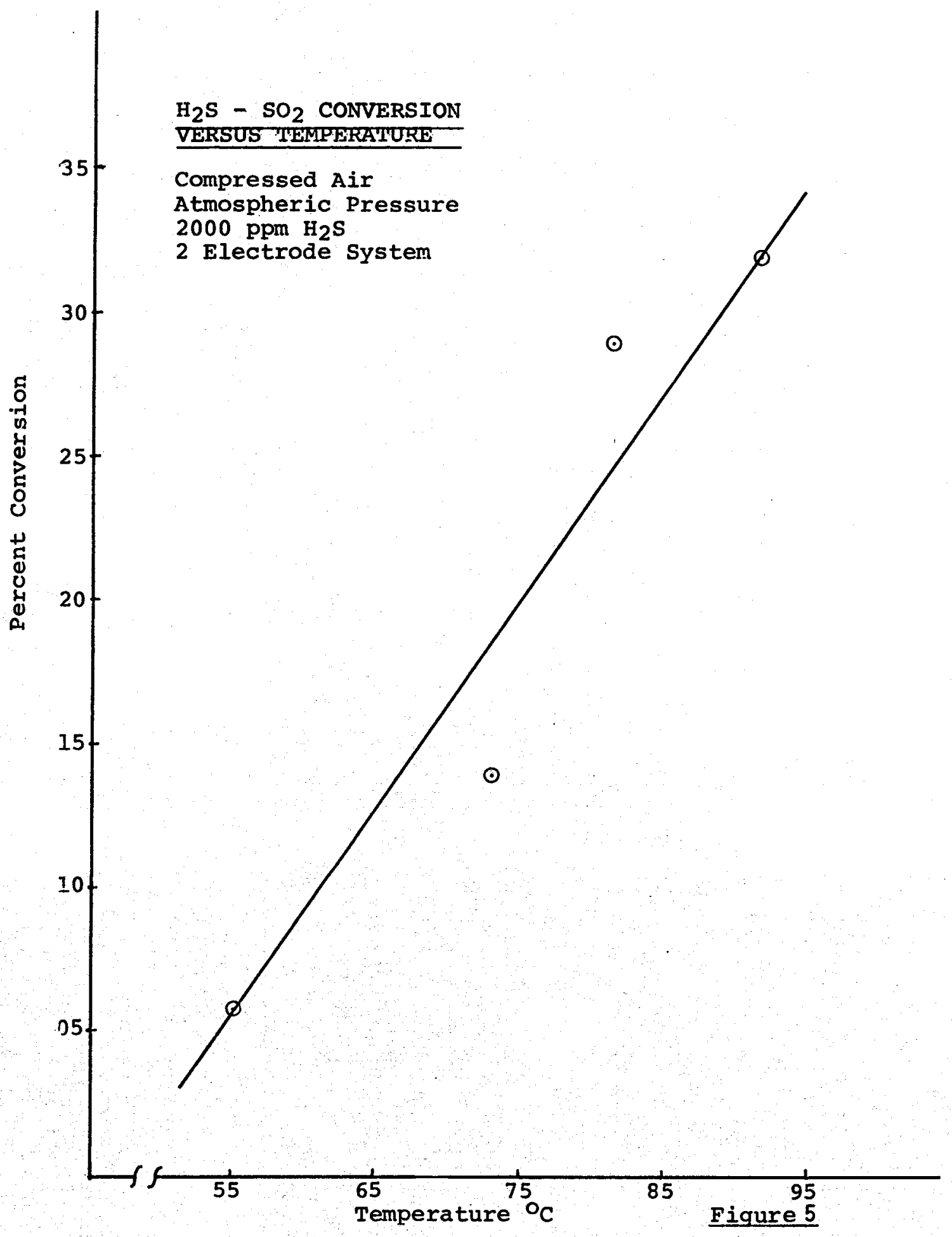

